\title{
Antisite Defects in Epitaxial Films of Lutetium Doped Yttrium Iron Garnets Studied by Nuclear Magnetic Resonance
}

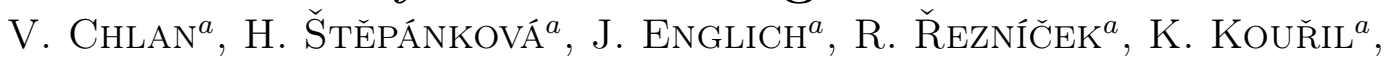
M. KuČERA ${ }^{a}$ AND K. NitsCH ${ }^{b}$

${ }^{a}$ Charles University in Prague, Faculty of Mathematics and Physics

V Holešovičkách 2, 18000, Prague 8, Czech Republic

${ }^{b}$ Institute of Physics, ASCR, Cukrovarnická 10, 16253 Prague 6, Czech Republic

\begin{abstract}
Series of lutetium doped yttrium iron garnet films is studied by means of ${ }^{57} \mathrm{Fe}$ nuclear magnetic resonance. Satellite spectral lines are resolved and identified in the spectra and concentrations of lutetium in dodecahedral sites as well as yttrium/lutetium antisite defects in octahedral sites are estimated. Compared to yttrium, lutetium cations are found to have stronger disposition towards creating the antisite defects.
\end{abstract}

PACS numbers: 75.50.Gg, 76.60.--k, 76.60.Lz, 68.35.Dv, 68.55.Ln

\section{Introduction}

Garnet films can be designed for various applications in optical, magnetooptical, and microwave devices $[1,2]$, where one of the important factors concerns information on intrinsic defects and substitutions [3, 4]. Such knowledge may be well acquired by nuclear magnetic resonance (NMR) spectroscopy for its high sensitivity to local structure perturbations.

The NMR method is particularly suitable for detection of intrinsic defects, impurities or aimed substitutions. The presence of such structural defect modifies locally the electronic structure, which reflects in a change of hyperfine interactions on neighbor nuclei and gives rise to characteristic shifts of their resonant frequencies. Moreover, the satellite spectral lines appearing in NMR spectra allow us to estimate the concentration of the defect from relative intensities of satellite lines with respect to their parent lines [5-7].

\section{Experimental}

The series of yttrium iron garnets (YIG) films doped by lutetium, $\mathrm{Lu}_{x} \mathrm{Y}_{3-x} \mathrm{Fe}_{5} \mathrm{O}_{12}$, was prepared by liquid phase epitaxy. The films of several micrometer thicknesses were grown on gallium gadolinium garnet substrates of crystallographic orientation $\langle 111\rangle$ using the lead-free $\mathrm{BaO}-$ $\mathrm{B}_{2} \mathrm{O}_{3}-\mathrm{BaF}_{2}$ flux. This non-routine technology minimizes the number of intrinsic defects and undesired impurities entering the structure [8]. In the melt containing garnet oxides $\mathrm{Fe}_{2} \mathrm{O}_{3}$ and $\mathrm{Y}_{2} \mathrm{O}_{3}$, the amount of dopant oxide $\mathrm{Lu}_{2} \mathrm{O}_{3}$ was consecutively increased. The molar ratio $R=$ $\left[\mathrm{Lu}_{2} \mathrm{O}_{3}\right] /\left[\mathrm{Y}_{2} \mathrm{O}_{3}+\mathrm{Lu}_{2} \mathrm{O}_{3}\right]$ was within the range $0-0.11$, the square brackets denote number of moles in the melt for each sample.

Pulse coherent NMR spectrometer with the Fourier transform and a homemade broadband NMR probe were used. ${ }^{57} \mathrm{Fe}$ NMR frequency-swept spectra of lutetium doped YIG garnets were measured at $4.2 \mathrm{~K}$ in zero magnetic field; spectral region corresponding to resonance of irons in tetrahedral $d$-sites is displayed in Fig. 1.

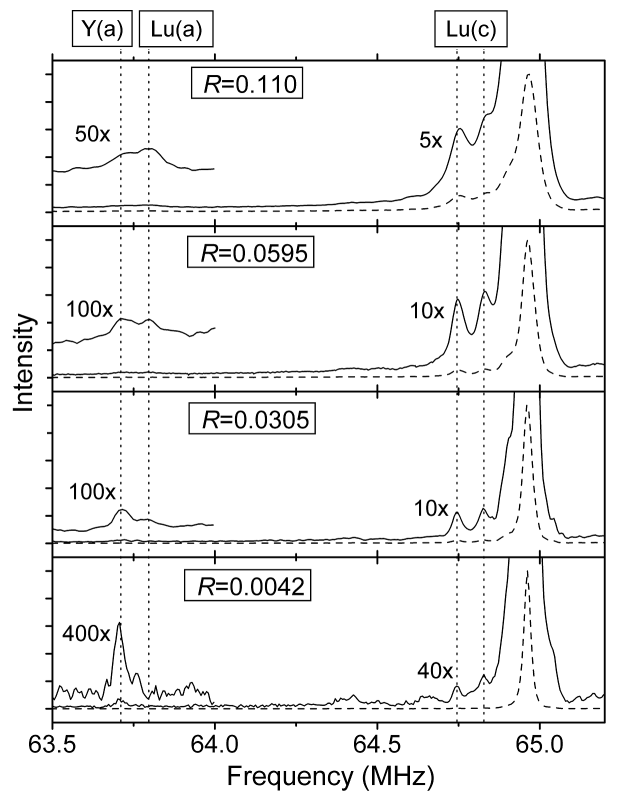

Fig. 1. ${ }^{57}$ Fe NMR spectra of lutetium doped YIG garnet films measured at $4.2 \mathrm{~K}$ in zero magnetic field. The molar ratio $R=\left[\mathrm{Lu}_{2} \mathrm{O}_{3}\right] /\left[\mathrm{Y}_{2} \mathrm{O}_{3}+\mathrm{Lu}_{2} \mathrm{O}_{3}\right]$ in melt is given for each spectrum. Only the spectral region corresponding to resonance of irons in tetrahedral d-sites is displayed. The vertical dotted lines under the labels $\mathrm{Y}(\mathrm{a}), \mathrm{Lu}(\mathrm{a})$, and $\mathrm{Lu}(\mathrm{c})$ denote positions of the corresponding satellites.

Besides the main (parent) resonance line at $64.964 \mathrm{MHz}$, we focused on two distinguished 
satellite patterns: two resolved satellites at 64.747 and $64.931 \mathrm{MHz}$, and two much weaker ones at frequencies 63.711 and $63.797 \mathrm{MHz}$. One should also note the nonzero background in NMR spectra that starts to appear with increasing concentration of lutetium, and is due to very broad lines of ${ }^{175} \mathrm{Lu}(\mathrm{c})$ resonance [9].

\section{Results and discussion}

As seen from the series of NMR spectra in Fig. 1, the intensity of satellite lines at 64.747 and $64.931 \mathrm{MHz}$ increases with content of lutetium in flux. These two satellites were identified as induced by $\mathrm{Lu}^{3+}(\mathrm{c})$, i.e., as the resonance of tetrahedral iron nuclei with one neighbouring dodecahedral yttrium replaced by a lutetium atom. They are only slightly shifted from the corresponding parent lines, which is in agreement with similar ionic radius and electronic structure of $\mathrm{Y}^{3+}$ and $\mathrm{Lu}^{3+}$.

The latter and weaker type of satellites is produced by antisite defects. Our assignment is based on comparison to satellite patterns in YIG and in LuIG. The satellite at $63.711 \mathrm{MHz}$ arises due to $\mathrm{Y}^{3+}$ defect in octahedral a-site, which agrees well with frequency of such satellite in YIG [6, 7], while the one at $63.797 \mathrm{MHz}$ corresponds to a similar scenario with $\mathrm{Lu}^{3+}$ cations in octahedral a-sites of LuIG [10] and to the dependence of frequency shift on ionic radius [10]. The intensity of $\mathrm{Lu}(\mathrm{a})$ satellite increases with lutetium content, and for highest Lu content it even exceeds the intensity of $\mathrm{Y}(\mathrm{a})$, which is found to be independent of $\mathrm{Lu}$ content.

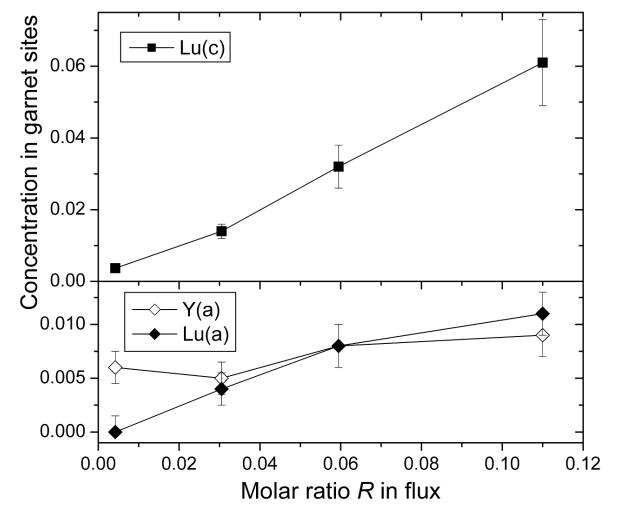

Fig. 2. Top: the dependence of Lu concentration $c_{\mathrm{Lu}(\mathrm{c})}$ in c-sites derived from NMR spectra on molar ratio $R=$ $\left[\mathrm{Lu}_{2} \mathrm{O}_{3}\right] /\left[\mathrm{Y}_{2} \mathrm{O}_{3}+\mathrm{Lu}_{2} \mathrm{O}_{3}\right]$ in the melt. Bottom: analogous dependence for $\mathrm{Y}$ and $\mathrm{Lu}$ antisite defects in a-sites.

NMR allows determining the concentration of a defect or a substitution in a particular crystallographic site from relative intensity of the induced satellite line and the parent spectral line. The dependence of acquired concentrations of $\mathrm{Lu}(\mathrm{c}), \mathrm{Lu}(\mathrm{a})$ and $\mathrm{Y}(\mathrm{a})$ on content of lutetium in the flux is displayed in Fig. 2. The concentration of lutetium in c-sites, $c_{\mathrm{Lu}(\mathrm{c})}$, depends linearly on $R$, however, the distribution coefficient given by $c_{\mathrm{Lu}(\mathrm{c})} / R$, which describes the segregation of lutetium between c-sites in garnet and the melt, is approximately 0.5 .
The concentration of $\mathrm{Y}(\mathrm{a})$ antisite defect is independent of $R$ within the experimental error, while $\mathrm{Lu}(\mathrm{a})$ concentration grows. Lutetium is distributed among octahedral and dodecahedral sites with relatively high ratio $\approx 0.16$ (for $R$ in the range $0.03-0.11$ ). For concentration of lutetium even as low as $5 \%$ of all c-sites, its occurrence in octahedral a-sites already exceeds the one of yttrium. This outcome is quite surprising, since the ionic radius of lutetium in octahedral coordination (100.1 pm) is only slightly lower (by 4\%) than that of yttrium (104.0 pm) [11].

\section{Conclusions}

By means of ${ }^{57} \mathrm{Fe}$ NMR we detected yttrium/lutetium antisite defects in octahedral sites of lutetium doped YIG and evaluated their concentrations. Lutetium cations are found to have stronger disposition towards creating the antisite defects than yttrium cations.

\section{Acknowledgments}

This work was supported by the project MS0021620834 of the Ministry of Education of the Czech Republic. R.r. also acknowledges the project SVV-2010-261303.

\section{References}

[1] T. Aichele, A. Lorenz, R. Hergt, P. Görnert, Cryst. Res. Technol. 38, 575 (2003).

[2] A.A. Serga, A.V. Chumak, B. Hillebrands, J. Phys. D, Appl. Phys. 43, 264002 (2010).

[3] A. Rogalev, J. Goulon, F. Wilhelm, Ch. Brouder, A. Yaresko, J. Ben Youssef, M.V. Indenbom, J. Magn. Magn. Mater. 321, 3945 (2009).

[4] W. Noun, E. Popova, F. Bardelli, Y. Dumont, R. Bertacco, A. Taliaferri, M. Tessier, M. Guyot, B. Berini, N. Keller, Phys. Rev. B 81, 054411 (2010).

[5] H. Štěpánková, P. Novák, J. Englich, K. Kohout, E.G. Caspary, M. Kučera, K. Nitsch, H. de Gronckel, J. Magn. Magn. Mater. 196, 412 (1999).

[6] P. Novák, J. Englich, H. Štěpánková, J. Kohout, H. Lütgemeier, K. Wagner, W. Tolksdorf, J. Phys. IV 7, C1-283 (1997).

[7] P. Novák, J. Englich, H. Štěpánková, J. Kohout, H. Lütgemeier, K. Wagner, W. Tolksdorf, Phys. Rev. Lett. 75, 545 (1995).

[8] M. Kučera, K. Nitsch, H. Štěpánková, M. Maryško, P. Reiche, Phys. Status Solidi A 198, 407 (2003).

[9] V. Chlan, P. Novák, H. Štěpánková, J. Englich, J. Kuriplach, D. Nižňanský, J. Appl. Phys. 99, 08M903 (2006).

[10] V. Chlan, H. Štěpánková, V. Procházka, J. Englich, J. Kohout, D. Nižňanský, J. Buršík, J. Magn. Magn. Mater. 290, 993 (2005).

[11] R.D. Shannon, Acta Crystallogr. A 32, 751 (1976). 